\title{
Partha Kar: Our responsibility to the next generation
}

\author{
Partha Kar consultant in diabetes and endocrinology \\ Portsmouth Hospitals NHS Trust
}

A fundamental problem with the NHS and its workforce issues sometimes tends to be us-the workforce itself. We can all make small changes that add up to making a big difference. Yet we shy away from them because we think they're too inconsequential, we're too beaten down by the process, or because, frankly, we don't care enough.

A classic example of this has been how doctors have looked after the next generation of the workforce. This issue of pastoral care often comes up when junior colleagues talk about not having leave requests granted, even for special occasions such as weddings. When these issues arise I wonder: where was the senior doctor involved who had responsibility for this individual? What stopped him or her stepping in?

This issue around leave may seem trivial, but it's extremely important in supporting our juniors. Older doctors get caught up in soul searching as to why we're failing to recruit doctors from the next generation, yet there are many examples of snide remarks and judgments from older doctors about junior colleagues. These are usually around the belief that junior colleagues "aren't tough enough" or are part of the "snowflake" generation.

As senior medics, are we engaged with the pastoral side of our role? Are we ensuring that the next generation of doctors actually want to do this job they have trained and worked hard for? Are we helping to make their working life a bit easier? It's never hard to fall back into discussing the difficulties we face and the age old debate about too few resources, a lack of support, and an ever growing burden of work.
But I'm mystified as to why that should translate into being rude to a colleague. This colleague is, after all, someone who's just learning to do a job, as we did ourselves a few years ago. Since losing the firm structure, little things can make consultants much more approachable: taking juniors for a coffee after the ward round, asking their names, inviting them to clinic, checking that they have their leave.

We worry about recruitment to our own specialty, but how many of us actually spend time showing its finer side - the very bits that drew us towards it? The responsibility for our own specialty, and its future, sits with us too.

A lot about the NHS system isn't within our control. But much of it is. If senior doctors don't play our part in trying to alleviate the daily workload and struggles of our trainees, I'm not sure that we can point fingers at others either. It doesn't cost much to smile or say a few encouraging words.

Being a senior medic comes with perks, challenges, and responsibilities. Our duties are not just to our patients but also to those who will one day take the baton. We have it in our power to stop approving soul destroying rota patterns or job plans that include fewer supplementary professional activities than we ourselves have. And, if we as doctors don't look after our own, who will?

Competing interests: I am associate national clinical director for diabetes with NHS England.

Provenance and peer review: Commissioned; not externally peer reviewed.

Published by the BMJ Publishing Group Limited. For permission to use (where not already granted under a licence) please go to http://group.bmj.com/group/rights-licensing/ permissions 